\title{
A survey on pulmonary screening practices among otolaryngology-head \& neck surgeons across Canada in the post treatment surveillance of head and neck squamous cell carcinoma
}

\author{
J Madana ${ }^{1 *}$, Gregoire B Morand', Luz Barona-Lleo², Martin J Black¹, Alex M Mlynarek and Michael P Hier ${ }^{1}$
}

\begin{abstract}
Background: Post treatment lung screening for head and neck cancer patients primarily focuses on the distant metastasis and a high rate of second primary can also be expected. The best screening tool and timing for this purpose is controversial. We sought out to assess the current practice and beliefs among Canadian Head and Neck Surgeons.

Methods: After Ethical Board approval, a nationwide survey was conducted through the Canadian Society of Otolaryngology (CSO) among head and neck surgeons regarding their practices for pulmonary screening in HNSCC patients.

Results: Our CSO survey among Otolaryngology-head and neck surgeons showed that 26 out of 32 respondents perform routine lung screen, out of which 23 (88\%) feel that chest radiography should be preferred. The majority of respondents felt that lung screening could impact beneficially on mortality. For symptomatic patients, low-dose spiral CT was the preferred modality (48\%), followed by PET/CT scan (14\%) and sputum cytology (14\%). In high-risk asymptomatic patients (current smoker, radiation exposure, family history and advanced HNSCC), 31\% of respondents performed a CXR. The same percentage performed a low dose CT, while 19\% relied on PET scan. A further 19\% of respondents did not perform any screening in high-risk patients. Most respondents (77\%) had more than 10 years practice since graduation from medical school and came from the provinces of Quebec, Ontario and Alberta.

Conclusion: Chest radiography remains the preferred modality for lung screening and was believed to be impacting beneficially on lung mortality. The recent literature does not seem to be in agreement with those beliefs. Further studies to establish which modality is best and concurrent nation-wide education are warranted.
\end{abstract}

Keywords: Head and neck cancer, Pulmonary screening, Survey, Canadian head and neck surgeons

\section{Introduction}

In head and neck squamous cell carcinoma patients (HNSCC), post treatment surveillance for distant disease is mostly focusing on the lungs, as HNSCC distant metastasis occurs in this organ in $90 \%$ of the cases and a high rate of primary of the lungs can be expected due to field cancerization of the entire upper aerodigestive tract

\footnotetext{
* Correspondence: maddyy@gmail.com

'Department of Otolaryngology-Head and Neck Surgery, Sir Mortimer B. Davis-Jewish General Hospital, McGill University, 3755 Côte Ste-Catherine Road, Montreal, QC, Canada

Full list of author information is available at the end of the article
}

[1-4]. Furthermore distant metastasis isolated to other sites such as liver or bones are rare in the absence of simultaneous pulmonary malignancy [4]. The traditional method for lung screening has been chest radiography, as it is widely available, cheap and has a low radiation dose, which allows for safe repetitive screening $[5,6]$.

Screening for distant metastasis and/or second primary of the lungs is useful as it allows for prognostication and adapted patient counselling [7] and in case of early detection may impact beneficially the prognosis of patients [8]. Early stage lung primary can be treated with curative 
intent [9] and some reports have claimed some benefit of metastasectomy in selected patients [8]. Overall, screening for distant metastasis has gained importance in the last few years, as aggressive locoregional treatment in HNSCC has led to better locoregional control but higher risk of distant failure [10]. This reverse failure pattern was first reported by Vikram et al. [10], who showed that only $15 \%$ of patients relapsed above the clavicle, as opposed to $70 \%$ in historical series.

Chest radiography is, however, likely to be out-dated, as previously shown by several groups [5,11]. Newer technologies now widely available such as computer tomography and positron emission tomography (PET/CT) are currently being evaluated as screening tools in HNSCC [4,5,12-14].

The objective of this study was to evaluate the current beliefs and practice among Head and Neck surgeon members of the Canadian Society of Otolaryngology using a nation-wide survey. The results of this survey were compared to latest data from the literature in the discussion.

\section{Methods}

After Ethics Review Board approval, a nationwide survey was conducted through the Canadian Society of Otolaryngology (CSO) among Otolaryngology-head and neck

Table 1 Structure of original questionnaire for nation-wide survey

\begin{tabular}{|c|c|c|}
\hline Questions & Possible responses & \\
\hline \multirow{6}{*}{$\begin{array}{l}\text { 1. How do you perform routine lung screening during } \\
\text { the post treatment follow-up of head and neck cancer }\end{array}$} & Lung radiography & All patients \\
\hline & Low-dose CT & Only symptomatic patients \\
\hline & $\mathrm{PET} / \mathrm{CT}$ & \multirow{4}{*}{$\begin{array}{l}\text { Only high risk patients (smokers, radiation } \\
\text { exposure, family history and advanced HNSCC, }\end{array}$} \\
\hline & Sputum cytology & \\
\hline & Physical exam & \\
\hline & No routine screen & \\
\hline \multirow{3}{*}{$\begin{array}{l}\text { 2. What is the frequency and duration of lung screening } \\
\text { in head and neck cancer during follow up in your practice }\end{array}$} & 5 years & Biennially \\
\hline & 10 years & Annually \\
\hline & Lifelong & Half-yearly \\
\hline \multirow{4}{*}{$\begin{array}{l}\text { 3. How effective do you believe the screening procedures } \\
\text { listed in question } 1 \text { are in reducing lung cancer mortality } \\
\text { during the follow-up of head and neck cancer }\end{array}$} & Very effective & \\
\hline & Somewhat effective & \\
\hline & No effective & \\
\hline & Don't know & \\
\hline \multirow{2}{*}{$\begin{array}{l}\text { 4. Have any of your patients during the past } 12 \text { months } \\
\text { inquired about lung screening }\end{array}$} & Yes & \\
\hline & No & \\
\hline \multirow{4}{*}{$\begin{array}{l}\text { 5. Number of years of your clinical head and neck } \\
\text { practice and years since graduation from medical school }\end{array}$} & $0-5$ years & \\
\hline & 6-10 years & \\
\hline & 11-20 years & \\
\hline & More than 20 years & \\
\hline \multirow{13}{*}{$\begin{array}{l}\text { 6. What is your practicing census region and the patient } \\
\text { volume during a typical week of your head \& neck practice }\end{array}$} & Alberta & <75 patients/week \\
\hline & Manitoba & \\
\hline & Saskatchewan & \\
\hline & British Columbia & \\
\hline & New Brunswick & 75-125 patients/week \\
\hline & Nova Scotia & \\
\hline & Prince Edward Island & \\
\hline & Newfoundland and Labrador & \\
\hline & Northwest Territories & >125 patients/week \\
\hline & Nunavut & \\
\hline & Ontario & \\
\hline & Quebec & \\
\hline & Yukon & \\
\hline
\end{tabular}


surgeons regarding their practices for post treatment pulmonary screening in HNSCC. A simple survey with 6 questions regarding actual practice was designed previously, reviewed, and sent to head and neck surgeons across Canada. A sample of the survey is available in Table 1.

\section{Results}

Our CSO survey among Otolaryngologist - Head and Neck surgeons showed that 26 out 32 (81\%) respondents perform routine lung screening, out of which 23 (88\%) feel that chest radiography should be preferred versus low dose CT scan or PET scan for annual pulmonary screening among all asymptomatic HNSCC patients during follow up (Figure 1). In asymptomatic patients, only 2 respondents did not perform any lung screening. The response rate of the survey was $84.2 \%$ (32 out of 38 ) and the survey was sent only once.

For symptomatic patients, low-dose spiral CT was the preferred modality (48\%), followed by PET/CT scan (14\%) and sputum cytology (14\%).

In high-risk asymptomatic patients (current smoker, radiation exposure, family history and advanced HNSCC), $31 \%$ of respondents performed a CXR. The same percentage performed a low dose CT, while 19\% relied on PET scan. A further $19 \%$ of respondents did not perform any screening in high-risk patients.

Seventeen of 28 respondents (60\%) request lung screening for 5 years, while 4 (15\%) and 7 (25\%) do it for 10 years and life long, respectively. Most respondents were screening their patients annually (74\%), while less than $15 \%$ did it biennially or half-yearly, respectively.

CXR was believed to be in $11 \%$ "very effective" and $50 \%$ "somewhat effective" in reducing lung malignancy mortality during HNSCC follow-up for non-smoker. In former smokers, the believed efficacy was $14 \%$ and $57 \%$, respectively. In current smoker, CXR was believed to be "very effective" and "somewhat effective" in $27 \%$ and $54 \%$, respectively. Seventy-four percent of respondents did not

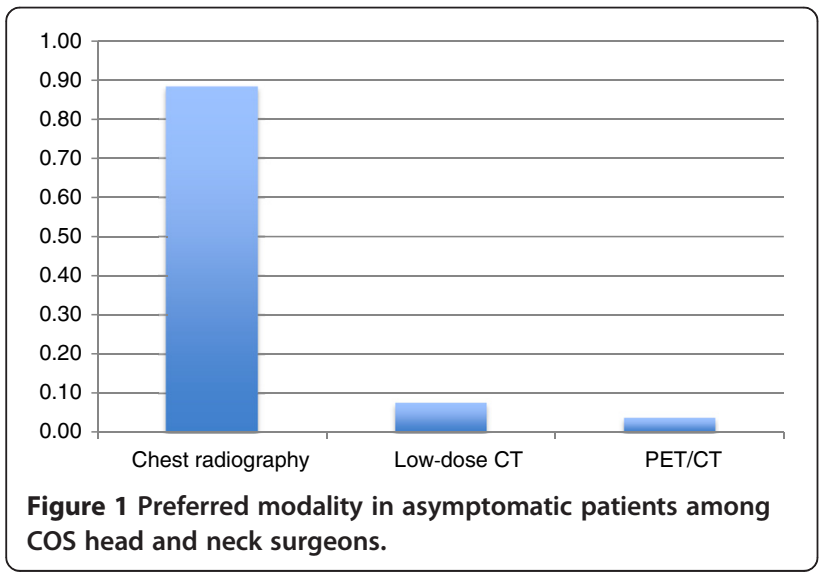

recall having any patient inquiring about lung screening in the past 12 months. Most respondents (77\%) had more than 10 years practice since graduation from medical school and came from the provinces of Quebec, Ontario and Alberta (11, 10, and 6, respectively).

\section{Discussion}

The main goal of this study was to assess the practice among head and neck surgeons in Canada for post treatment screening. Briefly, we showed that the preferred modality was chest radiography, done yearly in all patients for 5 years and this was believed in the majority of cases to be effective. Let us discuss each part of this statement point by point, in light of the classic Wilson and Jungner screening criteria (Table 2) [15].

\section{Target group}

As screening is less efficacious if the expected prevalence is low according to the Bayes theorem, screening has to target particular groups in order to be cost effective and avoid high rate of false positive [16]. Previous studies have shown that patients with advanced tumor stage, tumor from the hypopharynx and smokers are at higher risk for pulmonary malignancy [1,17-19]. In human papilloma virus patients, the rate of pulmonary malignancy may be lower due to lack of field carcinogenesis and a somewhat different distant metastatic pattern [20,21], thus requiring different strategies not only in treatment but also in surveillance.

\section{Screening accuracy and impact on mortality}

Although chest radiography remains the preferred and most widely used screening modality, numerous studies showed that regular chest radiography was not efficacious at detecting pulmonary malignancy [5,6,11]. More sensitive methods are required. Computer chest tomography

\section{Table 2 Wilson and Jungner screening criteria}

1. The condition sought should be an important health problem.
2. There should be an accepted treatment for patients with
3. $\quad$ Facilities for diagnosis and treatment should be available
4. There should be a recognizable latent or early symptomatic stage.
5. There should be a suitable test or examination.
6. The test should be acceptable to the population.
7. The natural history of the condition, including development from
8. There should be an agreed policy on whom to treat as patients.
9. The cost of case finding (including diagnosis and treatment
of patients diagnosed) should be economically balanced in
10. $\quad$ Case finding should be a continuing process and not a


(CT), positron emission tomography (PET/CT) and whole body MRI (WBMRI) are actually being evaluated $[4,5,12,13,22,23]$. CT is now widely available, has a reported sensitivity and specificity of $73 \%$ and $86 \%$, respectively [22] and recent development such as low dose CT may compensate for the relative high radiation dose of each examination, a factor particularly important for repetitive imaging such as in yearly screening [24]. For lung cancer, it was shown that LDCT could reduce mortality in some high-risk group such as smokers when LDCT was used as a screening tool [25]. A recent Cochrane systematic review came to the conclusion that LDCT could be beneficial in a high-risk lung cancer group, but not chest radiography or sputum cytology [26]. In HNSCC, to our knowledge, no trials are available yet.

$\mathrm{PET} / \mathrm{CT}$ is deemed to detect more metastasis and earlier in their course $[12,13]$. This advantage however could not be translated into clinical benefit for the patients in any studies $[4,13]$. It must be noted that most of the studies were retrospective and that the diagnosis of distant metastasis mostly did not change the treatment, as classically only symptomatic patients will receive palliative chemotherapy but no specific intervention was performed in early diagnosis patients [27]. Classically patients with distant metastasis are treated only when symptomatic, leading some authors to argue that screening may have low clinical impact, and is unlikely to change treatment course [27]. This may be true for distant metastasis, however second lung primary may be potentially treated with curative intent and thus remains important. Furthermore, when interpreting the literature, one should be cautious not to interpret the prolonged time between diagnosis and death as survival advantage, as this may be explained by lead-time bias [6].

Although PET/CT screens the whole body and this may seem like a critical advantage, a recent study by Spector et al. [4] showed that the most common site for asymptomatic metastasis were the lungs, whereas patients who developed bone, liver or brain metastasis were typically identified by imaging initiated by symptoms. This would suggest that screening (per definition in asymptomatic patients) may be sufficient if performed in the lungs only, as metastasis to other organs are likely to become rapidly symptomatic and not "detectable" in early disease course [4]. However, in the province of Ontario, PET/CT is not approved for routine pulmonary screening and therefore would not be an option for any surgeon responding from Ontario. PET/CT scan was believed to be useful for screening by $19 \%$ of respondents (2 from Quebec; and one from Saskatchewan, Alberta, British Columbia and New Brunswick each). Baring the Ontario respondents (10 in number, $31 \%$ of total), $27 \%(6 / 22)$ of the respondents from provinces other than Ontario think
PET/CT scan is a viable screening tool in high risk head and neck cancer patients on follow up. Finally newer studies have shown that WBMRI can be used as screening tool for HNSCC patients. WBMRI was shown in a pilot study to be accurate and not to require very long imaging times [23]. Further studies on that modality are required.

For sputum cytology, the scarce evidence available on that matter failed to support any potential use in HNSCC patients or any lung cancer case [26,28].

\section{Timing and frequency of screening}

To our knowledge, the adequate timing and frequency of screening for lung metastasis is based on empirical evidence. Most head and neck surgeons in Canada preferred yearly screening for 5 years. As distant metastasis most commonly occurs within 2 years after the diagnosis [29], one could wonder if half yearly screening in the first 2 years followed by yearly screening afterwards would be more adequate [30]. Again, although this may detect distant disease earlier in the course, it remains to be proven that this impacts survival beneficially and does not have negative impact on the health care system [31]. For screening tools with poor sensitivity such as chest radiography, a recent study showed it was ineffective when performed twice yearly [31].

\section{Conclusion}

Chest radiography remains the preferred screening modality for distant metastatic HNSCC in Canada, despite lacking sensitivity. Hence the lung screening practices of head and neck surgeons in Canada are contrary to what the evidence would suggest, and cannot be justified.

\section{Competing interests}

The authors declare that they have no competing interests.

\section{Authors' contributions}

Original idea by MJ and MPH. MJ designed and conducted the survey and gathered the data. GBM \& LBL performed statistical analysis, figures, which was reviewed and approved by $\mathrm{MJ}$ and $\mathrm{MPH}$. All authors read and approved the final manuscript.

\section{Author details}

'Department of Otolaryngology-Head and Neck Surgery, Sir Mortimer B. Davis-Jewish General Hospital, McGill University, 3755 Côte Ste-Catherine Road, Montreal, QC, Canada. ${ }^{2}$ Department of Otolaryngology-Head and Neck Surgery, Wayne State University, Detroit, MI, USA.

Received: 19 June 2014 Accepted: 16 January 2015

Published online: 04 February 2015

\section{References}

1. de Bree R, Deurloo EE, Snow GB, Leemans CR. Screening for distant metastases in patients with head and neck cancer. Laryngoscope. 2000;110:397-401.

2. Zbaren P, Lehmann W. Frequency and sites of distant metastases in head and neck squamous cell carcinoma. An analysis of 101 cases at autopsy. Arch Otolaryngol-Head Neck Surg. 1987;113:762-4. 
3. Slaughter DP, Southwick HW, Smejkal W. Field cancerization in oral stratified squamous epithelium; clinical implications of multicentric origin. Cancer. 1953;6:963-8.

4. Spector ME, Chinn SB, Rosko AJ, Worden FP, Ward PD, Divi V, et al. Diagnostic modalities for distant metastasis in head and neck squamous cell carcinoma: are we changing life expectancy? Laryngoscope. 2012;122:1507-11.

5. Warner GC, Cox GJ. Evaluation of chest radiography versus chest computed tomography in screening for pulmonary malignancy in advanced head and neck cancer. J Otolaryngol. 2003;32:107-9.

6. Engelen AM, Stalpers $\amalg$, Manni JJ, Ruijs JH. Yearly chest radiography in the early detection of lung cancer following laryngeal cancer. Eur Arch Oto-Rhino-Laryngol. 1992;249:364-9.

7. Roland NJ, Bradley PJ. The role of surgery in the palliation of head and neck cancer. Curr Opin Otolaryngol Head Neck Surg. 2014;22:101-8.

8. Florescu C, Thariat J. Local ablative treatments of oligometastases from head and neck carcinomas. Crit Rev Oncol Hematol. 2014;91(1):47-63.

9. Timmerman R, Paulus R, Galvin J, Michalski J, Straube W, Bradley J, et al. Stereotactic body radiation therapy for inoperable early stage lung cancer. JAMA. 2010;303:1070-6.

10. Vikram B. Changing patterns of failure in advanced head and neck cancer. Arch Otolaryngol. 1984;1 10:564-5.

11. Shah SI, Applebaum EL. Lung cancer after head and neck cancer: role of chest radiography. Laryngoscope. 2000;110:2033-6.

12. Xu G, Li J, Zuo X, Li C. Comparison of whole body positron emission tomography (PET)/PET-computed tomography and conventional anatomic imaging for detecting distant malignancies in patients with head and neck cancer: a meta-analysis. Laryngoscope. 2012;122:1974-8.

13. Huber GF, Zullig L, Soltermann A, Roessle M, Graf N, Haerle SK, et al. Down regulation of E-Cadherin (ECAD) - a predictor for occult metastatic disease in sentinel node biopsy of early squamous cell carcinomas of the oral cavity and oropharynx. BMC Cancer. 2011;11:217. 1-8.

14. Leong SC, Javed F, Elliot S, Mortimore S. Effectiveness of X-ray and computed tomography screening for assessing pulmonary involvement in patients with head and neck squamous cell carcinoma. J Laryngol Otol. 2008;122:961-6.

15. Wilson J, Jungner G. Principles and Practice of Screening for Disease. Geneva, Switzerland: World Health Organization; 1968. Public Health Papers 34.

16. Zwahlen M, Low N, Borisch B, Egger M, Kunzli N, Obrist R, et al. Population based screening - the difficulty of how to do more good than harm and how to achieve it. Swiss Med Wkly. 2010;140:w13061.

17. Alvi A, Johnson JT. Development of distant metastasis after treatment of advanced-stage head and neck cancer. Head Neck. 1997;19:500-5.

18. Kowalski LP, Carvalho AL, Martins Priante AV, Magrin J. Predictive factors for distant metastasis from oral and oropharyngeal squamous cell carcinoma. Oral Oncol. 2005;41:534-41.

19. McBride SM, Ali NN, Margalit DN, Chan AW. Active tobacco smoking and distant metastasis in patients with oropharyngeal cancer. Int J Radiat Oncol Biol Phys. 2012;84:183-8

20. Huang SH, Perez-Ordonez B, Liu FF, Waldron J, Ringash J, Irish J, et al. Atypical clinical behavior of p16-confirmed HPV-related oropharyngeal squamous cell carcinoma treated with radical radiotherapy. Int J Radiat Oncol Biol Phys. 2012;82:276-83.

21. Ruzevick J, Olivi A, Westra WH. Metastatic squamous cell carcinoma to the brain: an unrecognized pattern of distant spread in patients with HPV-related head and neck cancer. J Neurooncol. 2013;112:449-54.

22. Brouwer J, de Bree R, Hoekstra OS, Golding RP, Langendijk JA, Castelijns JA, et al. Screening for distant metastases in patients with head and neck cancer: is chest computed tomography sufficient? Laryngoscope. 2005;115:1813-7

23. Noij DP, Boerhout EJ, den Bos IC P-V, Comans EF, Oprea-Lager D, Reinhard R, et al. Whole-body-MR imaging including DWIBS in the work-up of patients with head and neck squamous cell carcinoma: A feasibility study. Eur J Radiol. 2014;83(7):1144-51.

24. Murano T, Minamimoto R, Senda M, Uno K, Jinnouchi S, Fukuda H, et al. Radiation exposure and risk-benefit analysis in cancer screening using FDGPET: results of a Japanese nationwide survey. Ann Nucl Med. 2011;25:657-66.

25. Humphrey LL, Deffebach M, Pappas M, Baumann C, Artis K, Mitchell JP, et al. Screening for lung cancer with low-dose computed tomography: a systematic review to update the US Preventive services task force recommendation. Ann Intern Med. 2013;159:411-20.
26. Manser R, Lethaby A, Irving LB, Stone C, Byrnes G, Abramson MJ, et al. Screening for lung cancer. Cochrane Database Syst Rev. 2013;6, CD001991.

27. Price KA, Cohen EE. Current treatment options for metastatic head and neck cancer. Curr Treat Options Oncol. 2012;13:35-46.

28. Rachmat L, Vreeburg GC, de Vries N, Hordijk GJ, Lubsen H, Manni JJ, et al. The value of twice yearly bronchoscopy in the work-up and follow-up of patients with laryngeal cancer. Eur J Cancer. 1993;29A:1096-9.

29. Hsu YB, Chu PY, Liu JC, Lan MC, Chang SY, Tsai TL, et al. Role of chest computed tomography in head and neck cancer. Arch Otolaryngol-Head Neck Surg. 2008;134:1050-4.

30. Stalpers LJ, van Vierzen PB, Brouns JJ, Bruaset I, Manni JJ, Verbeek AL, et al. The role of yearly chest radiography in the early detection of lung cancer following oral cancer. Int J Oral Maxillofac Surg. 1989;18:99-103.

31. Merkx MA, Boustahji AH, Kaanders JH, Joosten F, Marres HA, Bruaset I, et al A half-yearly chest radiograph for early detection of lung cancer following oral cancer. Int J Oral Maxillofac Surg. 2002;31:378-82.

\section{Submit your next manuscript to BioMed Central and take full advantage of:}

- Convenient online submission

- Thorough peer review

- No space constraints or color figure charges

- Immediate publication on acceptance

- Inclusion in PubMed, CAS, Scopus and Google Scholar

- Research which is freely available for redistribution 